\title{
Laparoscopic versus Open Appendectomy in Adults
}

\author{
Rohiya E. Hejazi ${ }^{1}$, Rakan M. Aljedaani ${ }^{2}$, Mohammed A. Alshehri ${ }^{2}$. \\ ${ }^{1}$ Faculty of Medicine, Ibn Sina College \\ ${ }^{2}$ Faculty of Medicine, King Saud bin Abdulaziz University for Health Sciences \\ *Corresponding Author: Rohiya E. Hejazi, Ibn Sina College, Jeddah, Saudi Arabia. Email: Rohiya.hejazi@gmail.com \\ Phone: 0555507294
}

\begin{abstract}
Background: Appendicitis is the most frequent surgical emergency. It affects people of all ages and gender. Methods to manage appendicitis are either medically by antibiotics and watchful waiting or surgery. The surgical approach includes laparoscopic and open appendectomy; neither surgical technique was proved to be the most efficient method to do an appendectomy. Objectives: comparison between laparoscopic appendectomy versus open appendectomy in regards to the complications, applicability, cost and hospital stay. Material and Methods: In this review, we used a comprehensive search of EMBASE, Pubmed, MEDLINE, Cochrane Central Register of Controlled Trials, and Cochrane Database of Systematic Reviews from January 1, 1995, to July 17, 2018.

Conclusion: Open appendectomy is the preferred choice in case of a perforated appendix or severe inflammation. Laparoscopic appendectomy offers fewer complications, hospital stay and lesser time in the operation room.
\end{abstract}

Keywords: appendectomy, laparoscopic, technique, appendicitis.

\section{INTRODUCTION}

Appendicitis is an inflammation of the appendix, which is a $31 / 2$-inch-long tube of tissue that extends from the large intestine ${ }^{1}$. Appendicitis is the most common cause of acute abdomen. Almost 40,000 hospital admissions in England are due to appendicitis ${ }^{2}$. It also affects 5.7-57/100,000 individuals and mostly adolescents and children ${ }^{3,4}$. The leading causes of variation in incidence are age, gender, and ethnicity ${ }^{4-6}$. The incidence of acute appendicitis peaks at the age of 10 and 30 years old ${ }^{7,8}$.

Appendectomy is considered the most common emergency surgery ${ }^{9,10}$. It is mainly diagnosed by ultrasound or computed tomography (CT) scan ${ }^{11,12}$. An adjournment in diagnosis and management has been reported in cases where pre and post-admission delay have occurred ${ }^{13}$. A study has shown that postponing appendectomy has a higher risk of progression to advanced disease ${ }^{13}$. If left untreated, the patient may develop appendix abscess, rupture, or generalized peritonitis ${ }^{11}$.

Laparoscopic appendectomy (LA) is considered the first therapeutic choice for acute appendicitis ${ }^{13,14}$. It has been linked to have a short hospital stay, less postoperative pain, and better wound healing ${ }^{15,16}$. In contrast, some studies have established that LA has a higher incidence of intra-abdominal abscesses and difficult applicability in complicated appendicitis surgery ${ }^{17}$. On the other hand, open appendectomy (OA) has shown to have low morbidity and mortality rate ${ }^{17}$. The controversy in literature will remain regarding the best method of an appendectomy.

In this study, we aimed at comparing the advantages and disadvantages of LA versus OA. Our objectives included a comparison between both types in regards to the complications, applicability, cost and hospital stay.

\section{MATERIALS AND METHODS}

\section{- Data Sources and Search terms}

The review was conducted using a comprehensive search of EMBASE, Pubmed, MEDLINE, Cochrane Central Register of Controlled Trials, and Cochrane Database of Systematic Reviews from January 1, 1995, to July 17, 2018. The used search terms were appendectomy, laparoscopic appendectomy, open appendectomy, laparoscopic versus open appendectomy and management of appendicitis.

\section{- Data Extraction}

Two independent individuals reviewed studies, abstracted data, and resolved the disagreement by consensus. Studies were evaluated for quality. A review protocol was followed in every part. 


\section{INDICATIONS}

Appendectomy has been considered an option for patients with appendicitis who experience fever, abdominal pain, or peritonitis with leukocytosis, but recent studies have shown that patients presenting with such symptoms can also be treated with antibiotics ${ }^{18}$ A study was conducted on 202 patients who presented with acute appendicitis and managed with antibiotics showed a recurrence rate of $13.9 \%{ }^{19}$. On the other hand, recurrence in surgery for appendicitis has rarely been reported since the duplication of the appendix is $0.004 \%-0.009 \%$ in the general population ${ }^{20}$. Patients who were treated by surgical approach may experience wound infection and hernia, which do not occur in patients who are treated with antibiotics ${ }^{21}$. However, post interventional peritonitis has been higher in patients who were treated with antibiotics ${ }^{22}$. A more extended hospital stay was reported in patients treated with antibiotics ${ }^{21}$. Even though studies have not found inferiority of antibiotics for appendicitis over surgical approach, Hanson has found that patients are more likely to choose surgical interventions over antibiotics for the treatment for acute appendicitis ${ }^{23}$. In general, regarding OA versus LA, there is no international agreement on which way is the best approach for an appendectomy.

\section{TECHNIQUE}

\section{- Open Appendectomy}

In 1891, McBurney was the first to describe $\mathrm{OA}^{24}$. In OA, the choice of anesthesia could be either general or spinal anesthesia. After general anesthesia induction, the abdomen must be re-examined, if a mass is felt it represents an appendiceal mass. In this situation, the incision might be done directly over the mass site, if not; the incision should be at McBurney's point. McBurney's point should be identified clearly before an incision is made. If the incision was placed extensively laterally, it might be too lateral to the abdomen cavity, and if much medially, it might expose the anterior rectus sheath rather than the oblique muscle. After making the incision, dissection in the subcutaneous tissue and the external oblique fascia should be done, followed by a sharp incision laterally to the rectus sheet. The external oblique muscle should be separated by muscle-splitting technique. The same method can be used to separate internal oblique and transversus abdominis muscle, then, carefully making a sharp incision in the peritoneum. Palpation is necessary to identify the exact location of the appendix. If adhesions were found, it could be dissected bluntly or sharply. Babcock-clamp is then used to grasp the mesoappendix; then absorbable sutures are used to tie the appendiceal artery. After that, the cecal wall around the appendix is sutured using nonabsorbable purse-string suture. A scalpel is used to excise the appendix after using a Kelly clamp to crush the appendiceal base. Finally, preventing a mucocele by cauterizing the remaining stump.

To close the incision, perineum, transversus abdominis, internal oblique and external oblique are closed using 2-0 absorbable suture. An injection of local anesthetic to the external oblique fascia may decrease the need of painkillers postoperatively, then, interrupted 3-0 absorbable suture is used to close Scarpa's fascia, and finally, staples or subcuticular sutures are used to close the $\operatorname{skin}^{25}$. In cases of a severely inflamed appendix and the possibility of perforation, retroperitoneal positioned appendix or an appendix surrounded by inflammatory tissue, a retrograde technique is preferred. The retrograde technique mainly starts by finding the appendix base first, then expose, ligate, and finally transect the appendix ${ }^{26}$.

Figure 1: Open Appendectomy Different Incision Methods.

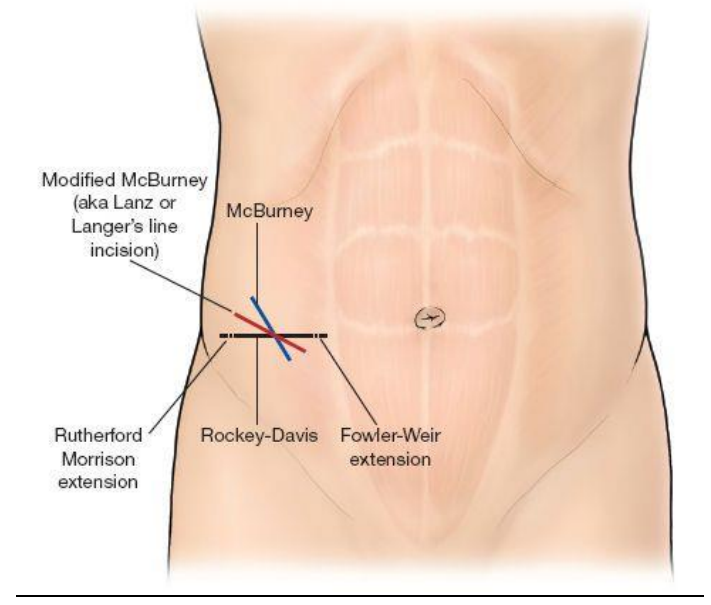

\section{- Laparoscopic Appendectomy}

Semm was the first to describe LA in $1983^{27}$. Typically, it is performed under general anesthesia with the insertion of an orogastric tube to decompress the stomach, and Foley's catheter to decompress the 
bladder. The video monitor is placed on the right side of the patient while the patient is supine. Inserting ports follows the principle of triangulation to maximize the exposure of the appendix. 12-mm peri-umbilical port is used for pneumoperitoneum. Two 5-mm ports are then placed in the suprapubic, and the left lower quadrant. Once locating the appendix, adhesions must be dissected bearing witness not to injure the right ureter and the iliac vessels. To dissect the mesoappendix, a Babcock-clamp is used. Laparoscopic gastrointestinal anastomosis stapler is used to divide the appendiceal base and the cecum. In some situations, to correctly place the staples, part of the cecum might be included. Removing the appendix after placing it in a specimen bag through the umbilical port decreases wound infection. Finally, irrigation with normal saline and closing the skin incisions ${ }^{25}$.

\section{Figure 2: Laparoscopic Appendectomy Steps.}

A
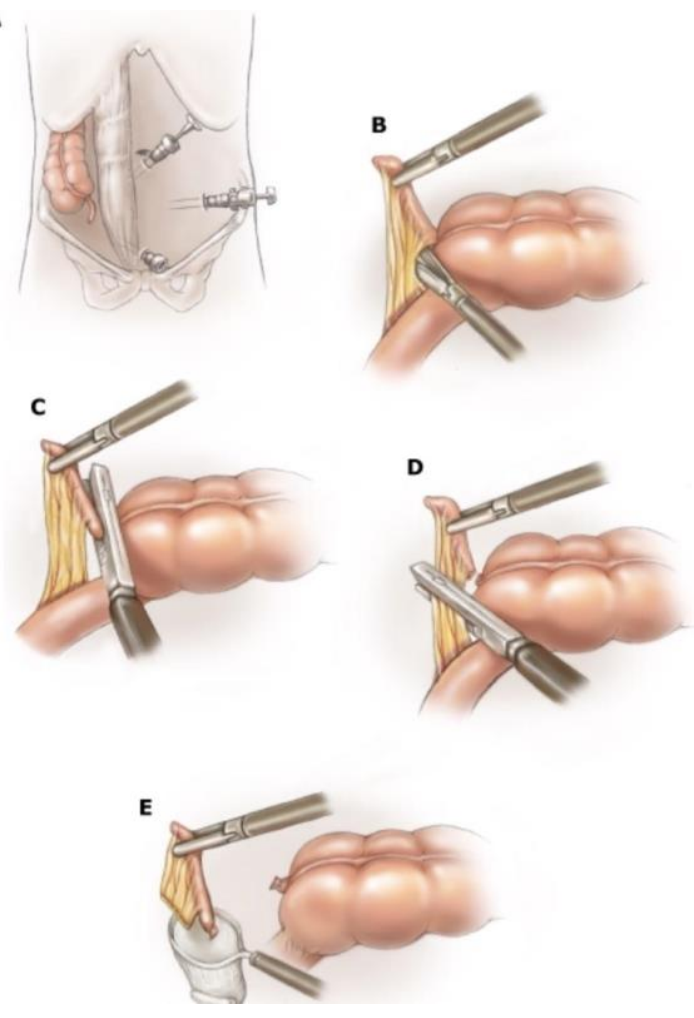

OPEN VS
APPENDECTOMY

LAPAROSCOPIC

Knowing the method that has fewer complications, cost and hospital stay direct surgeons for the optimum method to do an appendectomy. Many studies have been done to compare between LA and OA concerning efficacy and outcomes. A study on 533 patients found that the percentage of intraabdominal abscess in both methods is the same while surgical wounds' infections and incisional hernias were more common in patients who underwent $\mathrm{OA}^{28}$. These Findings were also comparable to other studies were conducted by Biondi, Mishra ${ }^{29}$. Decreasing the complication rate will lead to both better health and financial outcomes. Moreover, Two studies were conducted and had shown that the conversion rate from LA to OA was $7.3 \%$ and $16 \%$ which occurred mostly in cases of severe inflammation or ruptured appendix ${ }^{30}$. Mean operation time in LA was shorter than OA by an estimated average of 8.3-29 minutes in three different studies $^{30}$. Also, Studies have been done to compare the cost of both approaches. Kuwabara et al. have published a research in 2008 showing that LA costs is more than OA, while other studies found that there was no significant difference in the cost $(\mathrm{P} \text {-value }=0.164)^{30}$. Articles show controversy in postoperative pain where Kargar reported that patients underwent OA experienced less pain than LA and on the other side Mishra has established that patients after LA are more vocal to pain but have less severity ${ }^{29}$. Generally, hospital stay does not differ in both approaches, but some studies have suggested LA has a less hospital stay ${ }^{30}$. Unfortunately, there are not sufficient studies comparing the difficulty of teaching either method to neither surgical residents nor the time needed for the patients to return to normal daily activities post-operatively.

Table 1: Comparison between open versus laparoscopic appendectomy advantages

\begin{tabular}{|l|l|}
\hline Open Appendectomy & $\begin{array}{l}\text { Laparoscopic } \\
\text { Appendectomy }\end{array}$ \\
\hline $\begin{array}{l}\text { Effective in a ruptured } \\
\text { appendix and severe } \\
\text { Inflammation }\end{array}$ & $\begin{array}{l}\text { Fewer complications } \\
\text { (incisional hernias, and } \\
\text { surgical wound's } \\
\text { infection) }\end{array}$ \\
\hline Less cost & Less operation time \\
\hline Less pain & Less hospital stay \\
\hline
\end{tabular}

\section{CONCLUSION}


LA and OA are options to do an appendectomy, and they both have their advantages and disadvantages. LA presented a less frequency of complications such as surgical wounds' infection, and incisional hernia. OA can be a better option in cases of severe inflammation or ruptured appendix. For the patient's and hospital's benefit, OA is considered a cheaper option, although it takes a longer time in the operation room. Meanwhile, both techniques are performed depending on the surgeon, experience, and comfort. It is still difficult to decide which approach is better; more studies are needed to determine the most effective way.

\section{REFERENCES}

1. Available

from:

https://www.uptodate.com/contents/ acute-appendicitis-in-adults-clinicalmanifestations-and-differentialdiagnosis?search=appendicitis\&sou rce=search_result\&selected Title=3 $150 \&$ usage_type $=$ default $\&$ display_r ank $=3$

2. www.hesonline.nhs.uk/Ease/servlet/ ContentServer?siteID=1937\&catego ryID=202 .

3. Andersson R, Hugander A, Thulin A, Nyström PO, Olaison G(1994): Indications for operation in suspected appendicitis and incidence of perforation. BMJ., 308:107-110.

4. Wei PL, Chen CS, Keller JJ, Lin HC(2012): Monthly variation in acute appendicitis incidence: a 10-year nationwide population-based study. J Surg Res.,178:670-676.

5. Elangovan S, Knapp DP, Kallail KJ(1997): Incidence of acute appendicitis confirmed by histopathologic diagnosis. Kans Med., 98:10-13.

6. Walker AR, Shipton E, Walker BF, Manetsi B, Van Rensburg PS, Vorster HH(1989): Appendicectomy incidence in black and white children aged 0 to 14 years with a discussion on the disease's causation. Trop Gastroenterol., 10:96-101.

7. John M, Kirkwood KS (2008): Biological Basis of Modern Surgical Practice. Sabiston Textbook of Surgery. Philadelphia: Saunders Elsevier.
8. Chaitan K, Eden J, Daniel S, Angela S, Francois I (2011): Effect of delay in presentation on rate of perforation in children with appendicitis. Am J Emerg Med., 7(8):890-893.

9. Quartey B(2012): Interval appendectomy in adults: A necessary evil? J Emerg Trauma Shock, 5:213216.

10. Udgiri N, Curras E, Kella VK, Nagpal K, Cosgrove J(2011): Appendicitis, is it an emergency? Am Surg., 77:898-901.

11. De Castro MM, Unlu C, Steller EP, Van Wangersveld BA, Vrouenraets BC(2012): Evaluation of the appendicitis inflammatory response scores for patients with acute appendicitis. World J Surg., 7(7):1521-1524.

12. Sengupta A, Bax G, Peterson-Brown S(2009): White cell count and Creactive protein measurement in patients with possible appendicitis. Ann R Coll Surg Engl., 7:113-115.

13. Ditillo MF, Dziura JD, Rabinovici R(2006): Is it safe to delay appendectomy in adults with acute appendicitis? Ann Surg.,7:656-660.

14. Stewart D(2014): The management of acute appendicitis. Current surgical therapy, 8:252-255

15. Sakpal SV, Bindra SS, Chamberlain RS(2012): Laparoscopic appendectomy conversion rates two decades later: an analysis of surgeon and patient-specific factors resulting in open conversion. J Surg Res., 176(1):42-9.

16. McGrath B, Buckius MT, Grim R, Bell T, Ahuja V(2011): Economics of appendicitis: cost trend analysis of laparoscopic versus open appendectomy from 1998 to 2008. J Surg Res., 171(2):161-8.

17. Masoomi H, Mills S, Dolich MO, Ketana N, Carmichael JC, Nguyen NT et al.(2011): Comparison of outcomes of laparoscopic versus open appendectomy in adults: data from the Nationwide Inpatient Sample (NIS), 2006-2008. J Gastrointest Surg., 15(12):2226-31.

18. Salminen P, Paajanen H, Rautio T, Nordström P, Aarnio M, Rantanen 
T et al.(2015): Antibiotic Therapy vs Appendectomy for Treatment of Uncomplicated Acute Appendicitis. Obstetrical \& Gynecological Survey, 70(10):619-620.

19. Hansson J, Körner U, KhorramManesh A, Solberg A, Lundholm K(2009): Randomized clinical trial of antibiotic therapy versus appendicectomy as primary treatment of acute appendicitis in unselected patients. Br J Surg., 96(5):473-481.

20. Cave AJ(1936): Appendix vermiformis duplex. J Anat., 70:28392

21. Salminen P, Paajanen $H$, Rautio $T$ et al.(2015): Antibiotic Therapy vs Appendectomy for Treatment of Uncomplicated Acute AppendicitisThe APPAC Randomized Clinical Trial. JAMA., 313(23):23402348.

22. Vons C, Barry C, Maitre S et al.(2011): Amoxicillin plus clavulanic acid versus appendicectomy for treatment of acute uncomplicated appendicitis: an openlabel, non-inferiority, randomized controlled trial. Lancet., 377(9777):1573-79.

23. Hanson AL, Crosby RD, Basson M(2018): Patient Preferences for Surgery or Antibiotics for the

$\begin{array}{ll}\text { Treatment of } & \text { Acute } \\ \text { Appendicitis. JAMA } & \text { Surg., } \\ \text { 153(5):471-78. } & \end{array}$

24. McBurney C (1891): The Indications for Early Laparotomy in Appendicitis. Annals of Surgery, 13(4):233-54.

25. Available from: https://www.uptodate.com/contents/ management-of-acute-appendicitisin-adults .Available from: https://emedicine.medscape.com/arti cle/1582203-technique

26. Semm K (1983): Endoscopic appendectomy. Endoscopy, 15: 59-64

27. Sanchis C, Ramos D, Sos J, José JM, Coronel GA, Martín $\mathrm{R}$ et al.(2012): Apendicectomía laparoscópica frente al abordaje abierto para el tratamiento de la apendicitis agud., Revista de Gastroenterología de México, 77(2): 76-81.

28. Mishra R, Hanna G, Cuschieri A(2008): Laparoscopic versus Open Appendectomy for the Treatment of Acute Appendicitis. World Journal of Laparoscopic Surgery with DVD., 9:19-28.

29. Martin LC, Puente I, Sosa JL et al.(1995): Open versus laparoscopic appendectomy. A prospective randomized comparison. Annals of Surgery, 222(3):256-62. 